\title{
A Brief History and Overview of Existential-Phenomenological Psychology
}

\author{
Christopher Zieske* \\ Department of Psychology, Schreiner University, Kerrville, TX \\ bttps:/ / doi.org/10.33697/ ajur.2020.020 \\ Student:CMZies9417@schreiner.edu* \\ Mentor:jgallik@schreiner.edu*
}

\begin{abstract}
This article surveys the background and theory of the existential-phenomenological approach to psychology, with a particular focus on its reception in the United States. The article begins with a discussion of what exactly existential-phenomenological psychology is, including the theories underlying this approach and its basic practices. The article then discusses how the approach developed, including its roots in the philosophies of existentialism and phenomenology, its first appearances in Europe, its globalization, and finally its arrival in the U.S. The article then discusses struggles that the existential-phenomenological movement in psychology is currently facing and the concerns of those involved in the movement for its future. Finally, the article closes on a summary of all the information presented as well as of the contributions to the field of psychology that it and the existential-phenomenological movement can make.
\end{abstract}

\section{KEYWORDS}

Existentialism; Phenomenology; Psychology; United States; Existential Psychology; Phenomenological Psychology; Existential Psychotherapy; Philosophy of Psychology

\section{WHAT IS EXISTENTIAL-PHENOMENOLOGICAL PSYCHOLOGY?}

Existential-phenomenological psychology is an approach to psychology in all of its various subfields, although most prominently clinical and counselling psychology. This approach, which various regions throughout the world have come to recognize, ${ }^{1}$ has its roots in the continental philosophies of "existentialism" and "phenomenology." These two schools, though arising from different roots, soon became closely allied and now often come in tandem, which is reflected in the fact that existential psychology and phenomenological psychology are commonly viewed as the same thing. They are, however, two different schools of thought that simply tend to concur, and thus a discussion of what exactly each school is and the differences between the two of them is important to show how each may operate on their own, separately from the other. One should note that each of these terms represents a diversity of approaches within each school, and a single unifying definition for either "existentialism" or "phenomenology" is difficult due to the many disagreements in how each term should be defined. However, this paper will present the definitions seen by the author to most encompass all of the perspectives within each school.

The school of existentialism represents most fundamentally a philosophy and theory of human nature that attempts to turn its focus away from the normal focus of most philosophy and psychology on trivial, everyday concerns and toward a focus on deeper, more profound problems of human life. ${ }^{2-4}$ What these "profound problems" of human life are vary from one existential thinker to another; for instance, Medard Boss names them as human relationships with space, with time, human beings' acting through their body, the necessity for human beings to share a world with others, the necessity for human beings to constantly live in a mood, human beings' living in a historic context, and human beings' relationship with their own mortality. ${ }^{5}$ Yalom, on the other hand, specifies the relationship between humans and their freedom plus the consequent responsibility for their actions, existential isolation, meaninglessness, and mortality as the fundamental "existential issues" with which one is concerned throughout their life. ${ }^{6}$ Both of these theorists agree, however, that each of these issues represent more foundational problems of life than are commonly the focus within psychology, and that it is thus more important to gain an understanding of them. As can be seen, existentialism, both within the fields of philosophy and psychology, prefers to study more personal aspects of humanity than is the status quo in most other schools within these disciplines. Thus, existentialism refers primarily to a theory of what is important to understand about human beings and, in psychology, what topics a study should cover.

Phenomenology, on the other hand, is less of a theory of what should be studied, and more of a theory of how to study things. Phenomenology represents an attempt to move away from what most figures within the field call "natural science" approaches to studying human beings. These are the traditional scientific practices of attempting to observe phenomena and events from the 
outside as tangible, measurable, and predictable occurrences. Phenomenologists choose instead to point toward a study of human experience as a phenomenon in which the "within" and "without" are indistinguishable, and the "apparent within" of human subjects (i.e. their subjective experiences) is given equal attention to the "apparent without" (i.e. their observable behaviors). ${ }^{7}$ Phenomenology is often referred to as the study of "subjective experience", which is not far from the definition of phenomenology intended by most of the prominent figures of the school, but it can be misleading due its implications of viewing humans as subjects separate from the objects they encounter. In fact, phenomenology represents an attempt to transcend the split between subject and object that is so inherent in much modern scientific research, stemming from the Cartesian tradition of studying nature. The existential-phenomenological psychologist Emmy van Deurzen describes phenomenology as a methodology that "sets out to study subjectivity objectively and objectivity subjectively, whilst addressing the whole of human conscious experience in its complexity." 8 Phenomenology should therefore not be confused with such methods as introspection, which tend to isolate the human subject from their world. ${ }^{3}$

These two disciplines, as mentioned above, have had a history of close alliance to each other and are often studied reciprocally. This is most accredited to the philosopher Martin Heidegger, who, in his breakthrough work Being and Time, ${ }^{9}$ was the first to unite these two traditions into one study of ontology—or being — which inspired much of modern phenomenological research. Since the publication of Being and Time, the most customary practice within these two traditions was to combine them into one tradition, particularly in psychology. This resulted in their becoming nearly, although not entirely, identical to each other. Though they are often united, they remain their own schools of thought, and they may still occasionally be applied apart from each other. Most notably, phenomenological research methods are occasionally applied to the study of more commonplace subjects within psychology. Some scholars have stated that all existential psychology is a form of phenomenological psychology, but that the reversed statement isn't true; ${ }^{10}$ however, recent movements in psychology, such as the push for an "experimental existential psychology", ${ }^{11}$ seem to discredit this statement by developing an existential theory in psychology that does not use phenomenological methods of study. Despite their occasional separation from each other, this paper will focus specifically on the movements in psychology that combine the two traditions, and their applications both to psychological research as well as more applied areas in psychology (such as therapy or clinical interviewing). Please note that, as a mere survey of this intellectual discipline, this article will not serve as a comprehensive account of the history of the movement but will only serve as an introduction to those relatively unfamiliar with existential-phenomenological psychology.

\section{THE HISTORY AND DEVELOPMENT OF EXISTENTIAL-PHENOMENOLOGICAL PSYCHOLOGY}

\section{The philosophical roots}

Through the course of the nineteenth century two thinkers who had paradoxically never become acquainted with one another's works emerged in the Western world. Each of these thinkers had radical ideas that profoundly impacted many of the same groups of people. These thinkers were the Danish philosopher Søren Kierkegaard ${ }^{12-14}$ and the German philologist turned philosopher Friedrich Nietzsche. ${ }^{15-18}$ On the surface, these two thinkers would appear to have nothing in common with one another. Kierkegaard's works were firmly rooted in his Protestant faith—so much so, in fact, that his philosophy could be described as a kind of theology. Nietzsche, on the other hand, was fiercely atheistic, and placed himself in stark opposition to Christianity. However, upon a closer glance, one can easily find a spirit in each thinker's work that they shared. Most notably, both thinkers opposed the tendency in their times to turn one's focus away from the concrete, lived realities of human beings and towards abstract principles that exist outside of human experience. In Kierkegaard's case, these were the principles of a scientific and technological revolution which made human beings anonymous and made objects out of people, failing to pay proper attention to the significance of the human individual subject. In Nietzsche's case, this was a religion which reviled all human desires as evil and put its faith into a God assumed to be inherently better than humanity; a God which Nietzsche himself claimed to be dead in a notorious passage. ${ }^{15}$ Also important is that both thinkers were fiercely critical of the tendency they observed in humans to lose themselves in trivial, everyday pursuits, and in mindless conformity to the masses. Kierkegaard and Nietzsche sought, in their philosophies, to bring concern back to the deeper questions of an individual person's life, thus providing the foundations for existential philosophy.

Many years after Kierkegaard, and shortly after Nietzsche, Edmund Husserl7, 19, 20 founded the school of phenomenology—a school that was at that point not yet connected to existentialism. Husserl found fault with the accepted methods of studying the world during his time and developed a philosophy that would eliminate some of the biases that were inherent in these methods. Husserl was inspired by a series of lectures by Franz Brentano on the concept of "intentionality," or the tendency of human consciousness to direct itself towards specific objects and apprehend them as they appear to this consciousness.A, 2, 7 This led Husserl to propose a philosophy that sought to study phenomena "as they appear,"” naming this method "phenomenology". Husserl borrowed this term from other philosophers who had used it before, such as Immanuel Kant and Georg Wilhelm Friedrich Hegel, but Husserl was the first to establish "phenomenology" as its own discipline. Husserl sought to design a method of analysis in which, rather than analyzing the phenomena that one encounters, one rather analyzes their state of consciousness when encountering these phenomena to better understand the phenomena as they present themselves without bias. This called 
for a suspension of the preconceptions that one carries from their personal and cultural experiences—a process which Husserl named "bracketing." When applying the concept of "bracketing," one must essentially examine the assumptions which they make when first exposed to a phenomenon. Upon identifying these assumptions, one is encouraged to set them aside for the time being in order to better understand the phenomenon simply "as it appears" and without bias. As one is able to identify and "bracket out" more such assumptions, one is assumed to be gaining a better understanding of the phenomenon which they are encountering. In particular, Husserl placed much emphasis on bracketing out the "natural scientific" attitude towards phenomena, referring to the Cartesian-rooted tradition of separating the phenomenon from its background and even from oneself-it should be recalled that phenomenology rejects the split between "subject" and "object." This concept of bracketing is significant to the various psychological research methods developed in the name of phenomenology; primarily qualitative research methods which require one to "bracket out" one's own assumptions and biases regarding the topic of interest in a study so that one may better understand the experiences of one's participants.

Martin Heidegger, one of Husserl's students, was familiar with all of the thinkers mentioned above, and synthesized their thinking into a "phenomenological ontology" in his esteemed tome, Being and Time, ${ }^{9}$ as mentioned above. ${ }^{\mathbf{B}}$ In this work, Heidegger does not necessarily seek to present a study of buman being specifically, but rather an analysis of existence at large. However, Being and Time still contained many valuable insights into human nature because of its grounding in ontology, or the philosophical study of being. Most notably, Heidegger discusses his concept of "Dasein" (literally: being-there, usually interpreted to mean "presence"), which refers to human consciousness and its drive to make meaning out of the world and the person's own relation to the world. In Heidegger's words, "Dasein is an entity which... in its very Being, that Being is an issue for it... Dasein, in its Being has a relationship towards that Being — a relationship which itself is one of Being." Heidegger conceptualized the human "Dasein" as an entity which must constantly reflect upon its own Being in relation to the Being of the world in which it exists, thus providing a foundation upon which human psychology could be studied and understood. Heidegger is thus commonly credited with being the first existential phenomenologist, although he rejected being ascribed such titles as "existentialist" due to their misleading tendency to label his philosophy (which can, and has, resulted in much confusion over what exactly can be considered "existentialism.") Nevertheless, Heidegger very well may be the philosopher who has had the most influence on the existentialphenomenological approach to psychology, and much of the movement's assertions should be credited to their roots in his thinking. ${ }^{21}$

Aside from spearheading the movement of "existential phenomenology," however, Heidegger made yet another major contribution to the tradition of phenomenology: he highlighted the importance of hermeneutics, or the practice of understanding texts and dialogue through interpretation, to phenomenological investigations. Where Husserl's phenomenology attempted to remain strictly descriptive, seeking to understand phenomena as they present themselves without the preconceptions provided to one by cultural, historical, and linguistic preconceptions, Heidegger understood humans as fundamentally cultural beings, who always come from historical and linguistic backgrounds that both facilitate one's understanding of a phenomenon and limit such an understanding. Heidegger also saw humans as beings that always have predispositions as a result of their earlier experiences: "Interpretation is grounded in something we have in advance-in a fore-having." Thus, understanding a phenomenon "as it appears" cannot, in Heidegger's philosophy, end at a mere description of the phenomenon, but must necessarily include an interpretation of this description in terms of the personal and cultural background of the person providing the description. Where Husserl saw the task of the phenomenologist as one of "bracketing out" one's biases, Heidegger acknowledged that a complete bracketing of one's biases is not possible, and proposed instead that one could use their own assumptions to facilitate their understanding of a phenomenon while seeking to engage in discourse with those who carry alternate assumptions. This method of acknowledging the role which one's assumptions play in their understanding a phenomenon while seeking to balance this with the assumptions of others is known as the "hermeneutic circle." This approach to phenomenology provides the foundations of the "hermeneutic" phenomenological method, in contrast to the "descriptive" or "empirical" method rooted in Husserl's thinking. 22

Heidegger's work was heavily criticized, however, for some of its excessive individualism. One should recognize that Heidegger had set out to correct some of the individualism overabundance found in Kierkegaard and Nietzsche's works, positing every existence as a "being-in-the-world" which must always exist in relation to their world. Heidegger also presented the concept of a "care structure" in human consciousness, which does involve the recognition of one's responsibilities for others. Nevertheless, Heidegger's philosophy still seemed to prioritize an individual's reflection on their own existence, with other people being primarily encountered as obstacles. Limited room is given for empathic reflection on the other's existence as one reflects on their own existence. Such issues in Heidegger's philosophy became even more relevant when Heidegger joined the National Socialist Party, revealing his anti-Semitic biases. Suddenly, Heidegger's concept of "Dasein" did not seem to apply to people of Jewish heritage, which presented a severe flaw in Heidegger's thinking. This led to various re-developments of Heidegger's philosophy among his students, including the Jewish existentialist Emmanuel Levinas. Levinas refined Heidegger's thinking to include Dasein's reflection on both its own existence and that of others in his concept of the "Face," or the other's assertion of their own 
subjectivity onto the individual. This "Face" forces one to recognize the "Other" as also embodying Dasein. ${ }^{23}$ Such contributions as is found in Levinas' and others' (such as Hannah Arendt's and Herbert Marcuse's) re-inventions of Heidegger's thinking helped pave the road to the application of existential phenomenology in therapy — a situation in which the therapist and the client must both recognize each other as embodying Dasein.

Very soon after the time of Heidegger and his students' works, the ideas of these thinkers began to gain interest among a group of French philosophers. Among the most famous of these philosophers were Jean-Paul Sartre ${ }^{24,25}$ and Simone de Beauvoir. ${ }^{26,27}$ Sartre was, in fact, the first thinker to place the name of "existentialism" onto his philosophy, and included Kierkegaard, Karl Jaspers (see below), Heidegger, and various other thinkers in his list of people who could also be considered a part of the movement, ${ }^{25}$ even though none of these thinkers explicitly used the term to describe their own philosophies. Sartre's major work consisted primarily of a series of responses to all of these thinkers, expanding upon their ideas and, in some cases, refining the aspects of their philosophies that he believed to fall short of reality. The term "existentialism" is most attributed with Sartre, and it is Sartre's take on the philosophy that most commonly comes to people's minds when they hear the term. This has caused much confusion as to what "existentialism" is, as Sartre's philosophy is radically different from many of these authors who did not explicitly use the term and even occasionally rejected it. To most existential psychologists, however, any philosopher who sought to focus on the deeper concerns of human existence over the more trivial concerns of it could be considered a part of the movement. Some propose using such terms as "existential philosophy"2 or "philosophy of existence" 28 instead of "existentialism" to refer to the movement. This is intended to both respect some thinkers" wishes not to be placed under a restrictive label while still acknowledging their influence on the existential movement in psychology. This is thus the definition for "existentialism" (or "existential philosophy," if preferred) that will be used in this paper.

Jean-Paul Sartre's most notable contribution to the application of existential phenomenology in psychology is his famous (and somewhat controversial) statement that "existence precedes essence." This seemingly esoteric phrase carries a surprisingly straightforward meaning: it refers to Sartre's idea that human beings are not given a prescribed purpose, or "essence", but are rather tasked with creating this "essence" for themselves. Sartre saw humans as fundamentally free creatures and believed that there are essentially no pre-deterministic forces that shape a person's actions, decisions, or identity. ${ }^{24}$ While this position may seem extreme at first glance, Sartre was, in reality, ready to acknowledge that there were limitations placed upon human freedom. Drawing upon Heidegger, for instance, Sartre did acknowledge that human beings are not able to choose which cultural and historical context in which they are born, nor various other aspects of their conditions. However, according to Sartre, humans retain the freedom to respond to these limitations in any number of ways and are thus still fundamentally free. This freedom, however, comes with the weight of responsibility which one has for their own actions, and ultimately for the entire world. ${ }^{25}$ Freedom, then, is not necessarily praised as a blessing as it is in other philosophies, but rather is seen as a given aspect to human existence which all humans must face, and which presents human beings with both liberties and challenges.

Sartre also contributed to the existential-phenomenological movement in psychology by formulating his recreation of psychoanalysis, which he terms "existential psychoanalysis." This system re-established the foundational ideas behind psychoanalysis to place more emphasis on existential concerns than on the aspects of humanity on which classic psychoanalysis focuses, such as sexuality or overcoming an inferiority complex. ${ }^{24}$ It also attempts to look for the "projects" which one undertakes for their existence, with "projects" referring to the purposes or ideals that one sets out to fulfill. Existential psychoanalysis sees these "projects" as a defining feature of one's life and the meanings which one creates in their psyche. ${ }^{24}$ These ideas particularly influenced certain existential psychologists who synthesize existential-phenomenological practice with psychoanalytic therapeutic techniques, such as Rollo May. ${ }^{29}$

Unfortunately, Sartre's fellow author, Simone de Beauvoir, tends to be overlooked in comparison to him, despite her also remarkably high influences on the movement of existentialism. Sartre and de Beauvoir influenced each other's work a great deal, and de Beauvoir proposed many radical ideas in her philosophy that the existentialists before her had not yet dared to make. One of her greatest contributions was applying existential concepts to the movement of Feminism, as she used Sartre's mantra of "existence precedes essence" as a basis for her critique of gender roles in her notorious quote: "One is not born but becomes a woman."26 This greatly influenced the Feminist movement as well as the movement for transgender rights, and de Beauvoir is partially responsible for developing the idea of the sex-gender split with her emphasis on distinguishing between the biological givens of sex and the culturally created prescriptions of gender.$^{30}$ De Beauvoir's philosophy was also known to be more explicitly prosocial than Sartre's, as de Beauvoir frequently discussed the necessity of contributing to the welfare of others in order to achieve true freedom. ${ }^{27}$ De Beauvoir also expanded upon Sartre's views of social relations to include not only conflict as a fundamental aspect of social confrontations but also mutuality and reciprocity. ${ }^{2}$

Though not listed in quite as much detail here, many other figures have also been influential on the development of existential and phenomenological philosophy. For instance, Martin Buber proposed a distinction between "I-Thou" experiences, or 
experiences in which two people meet each other as equally present entities and are open to shared experiences, and "I-it" experiences, in which people encounter others with attitudes of indifference and treat others much like objects. ${ }^{31}$ These descriptions of such experiences gained Buber wide credit as a major contributor to existential thought. Also important is Karl Jaspers, who, as shall be seen below, was originally a psychiatrist who then turned to existential philosophy to gain a fuller understanding of humanity. Maurice Merleau-Ponty was also well known for his contributions to existential-phenomenology and was particularly known for refuting the distinction between mind and body that was present in most thinkers from Descartes onwards. ${ }^{32,33}$ Many other figures were significant, of course, but to attempt to list them all would be difficult to do in a single article.

Existential-phenomenological psychology's beginnings in Europe

At around the same time that the thinkers listed above were developing "philosophical anthropologies" "philosophies of existence", many psychiatrists and psychologists in Europe began to take an interest in their ideas and apply them to a "scientific anthropology" of their own design. One of the first figures to do this was the Psychiatrist Karl Jaspers, who helped to pave the road on which existential-phenomenological approaches to psychology and psychiatry could come into existence. Jaspers earned his degree in Psychiatry from the University of Heidelburg; however, feeling disenchanted with the incomplete perspective on humanity prominent in psychiatric study, he then turned to philosophy to assist in providing a more complete picture of humanity for psychiatric study. The most prominent work in which Jaspers used existential philosophy to supplement psychiatry was his two-volume tome General Psychopathology. ${ }^{34} \mathrm{I}_{\mathrm{n}}$ this work, Jaspers introduces the practices of psychopathological study and also gives his critique of some of the traditions in the field. General Psychopathology is a breakthrough work in the field of psychiatry which represents one of the first efforts to inform psychiatric and psychopathological study of the issues expounded upon by existential philosophers. Eventually Jaspers even ended up becoming less of a psychiatrist and more of a philosopher, giving lectures on philosophy and publishing philosophical works rather than applying himself to work with clinical cases. ${ }^{2,28}$

Another important contribution of Jaspers' was his introduction of phenomenology as a research method in the field of psychopathology. Jaspers was one of the first in any of the fields of psychiatry, psychology, or psychopathology to begin arguing for the necessity of phenomenological research in these fields. ${ }^{35} \mathrm{He}$ was also one of the first to begin using it. General Psychopathology even dedicates an entire chapter to describing some of the phenomenological research conducted up to the time of the work's publication on various abnormal psychic phenomena. This application of phenomenological methods to research and analysis in psychiatry then influenced various psychiatrists writing after him, such us Eugene Minkowski, Erwin Straus, and Viktor von Gebsattel. ${ }^{\mathrm{E}, 36}$

However, Jaspers' approach was not yet truly "existential psychiatry," as his work in psychiatry was not yet a thorough dedication of his studies to understanding human confrontations with existential dilemmas - rather, Jaspers' work took more of a flavor of a psychiatry that allowed existential philosophy to inform its practices to some extent. This fact is even further emphasized by the fact that Karl Jaspers eventually began to give up on psychiatry and become more of a philosopher, which only further contributed to the split between scientific psychology and philosophy. Rather than Jaspers, the first figures to synthesize existentialism with the fields of psychiatry and psychology were those in the school of Daseinsanalysis. ${ }^{\mathrm{F}}$ This movement was spearheaded by the psychiatrist Ludwig Binswanger, ${ }^{\mathbf{G}}$ whose work was one of the first to begin applying phenomenological research methods not only to understanding psychopathological phenomena, but also to concerns of human existence. By observing how his clients related to the world around them and attempted to find meaning in it, Binswanger laid the groundwork upon which all of existential-phenomenological psychology would from then on be based. "36 Binswanger first referred to his school of psychiatric study as "phenomenological anthropology," but then later termed it "Daseinsanalysis," directly referencing the Heideggerian concept of human "Dasein."H Binswanger was thus the first to give his psychiatric approach a name with a distinctly existential flavor, in contrast to Jaspers' more universal approach to psychiatry.

Following in Binswanger's footsteps was the psychiatrist Medard Boss. ${ }^{5}$ Aside from his roots in Binswanger's thinking, Boss also studied with Martin Heidegger for many years and based much of his approach to psychiatric work on Heidegger's ideas. ${ }^{2,3}$ Boss, like Binswanger, referred to this approach as "Daseinsanalysis" in reminiscence of Heidegger. Boss continued Binswanger's dedication to studying psychiatric patients' encounters with their world and attempts to make meaning out of this world. However, Boss was even able to develop this practice further than Binswanger, becoming the first figure in the history of psychology and psychiatry to develop a specifically existentially-oriented psychotherapy. This earned Boss the honor of becoming one of the most influential figures in the entire history of existential-phenomenological psychology. He is especially revered in Europe, where he is upheld as the single most influential founder of existential-phenomenological approaches to psychology for the region. ${ }^{3}$ 
Daseinsanalysis is frequently seen as an attempt to integrate existential thought into psychoanalysis and does indeed involve this to some extent. In reality, though, Daseinsanalysts tended to be highly critical of much psychoanalytic thinking, especially classic Freudian psychoanalysis. ${ }^{5,36}$ Binswanger and Boss themselves would likely have described their approach more as an analysis of how human beings relate to their world, and how this relationship with their world influences their thoughts, feelings, actions, etcetera. Both thinkers had received some experience in psychoanalysis before turning to "Daseinsanalysis" and, having seen psychoanalysis in action firsthand, both were aware of some of the dangers of using this approach. This would set in motion a dilemma in the movement of existential-phenomenological psychology that to this day has not been resolved; this being the dilemma over how much influence psychoanalysis should have over existential-phenomenological psychology.

Daseinsanalysis, however, was not the only variant of existential-phenomenological psychology in existence. Many other schools of existential-phenomenological thinking also began to emerge after Daseinsanalysis rose into prominence. Another of the most notable schools of existential-phenomenological thinking was Logotherapy, conceived by the Austrian psychiatrist Viktor Frankl. Frankl developed this therapeutic approach largely in response to his experiences in a concentration camp during the National Socialist regime. During his time in the camp, he noticed that it was the people who were able to find a meaning in what was happening to them, even if it seemed meaningless, who were best able to survive all of the grueling treatments that they suffered at the hands of the SS. At the end of World War II, after finally being freed from the concentration camp, Frankl began writing his signature work, Man's Search for Meaning, ${ }^{37}$ which would come to be seen as the key text for Logotherapeutic practice and would rise to a prominence even rivaling that of Daseinsanalysis. In Man's Search for Meaning, Frankl presents his view of humanity as a species which is constantly tasked with giving their life a meaning. People who can find a meaning for each experience they have can withstand nearly any struggle, even the most painful and damaging, with resilience. Thus, Frankl's practice of Logotherapy largely involves encouraging clients to find meaning within their circumstances, thus making these circumstances more bearable and allowing the client to live a more fulfilled life. While Frankl did not emphasize ideas of inherent meaninglessness in life as much as other existential thinkers, such as Sartre ${ }^{24,} 25$ and Yalom, ${ }^{6}$ he did acknowledge that it was perhaps more apt to encourage people not to inquire about the meaning of life but rather to perceive the universe as asking them what would be the meaning of their life. ${ }^{37}$

Writing close to the same time as Frankl, R.D. Laing began developing his own existential approach to psychotherapy in the United Kingdom. Laing, a psychiatrist, was highly influenced by a movement in the UK during the time of his writing which the psychiatrist David Cooper called "anti-psychiatry," although many of his colleagues (including Laing) were less certain about using this label. This movement was characterized by a renewal of skepticism in the traditional teachings of psychiatry. In the case of Laing and Cooper, this took on a particularly existential tone, with both figures being highly influenced by Sartrean ideas and taking up Sartre's call to rebel against those authorities who abuse their power. Laing and Cooper believed that many psychiatrists, upon being put in a place of power over their patients, abuse this power to invalidate their "madness" instead of truly recognizing the necessity of this "madness" for the patients. Laing began developing a radical psychiatric approach that saw the goal of therapy and treatment not as curing psychiatric disorders, but rather engaging with people using their seemingly "mad" state and reciprocally getting them to engage in these states. He and Cooper notoriously argued that it may be the patients, in fact, who were the most sane, as their psychiatric "disorder" may simply be their breakthrough from the ordinary delusions that "normal" people allow themselves to have. ${ }^{2}$ Laing's existentially oriented approach to psychiatry eventually mellowed out over the course of his career from this rather extreme form of existential therapy; however, he never put an end to the trademark existential practice of entering into his patients' worldviews (rather than basing his treatments off of his own psychiatric worldview) and zealously encouraging them to confront the reality of their situations directly. Laing's novel approach to therapy would go on to influence an entire school of existential-phenomenological research and therapy known for most of its history as the British School of Existential Psychotherapy, ${ }^{\mathbf{I}}$ developed by such figures as Emmy van Deurzen, Ernesto Spinelli, and Hans Cohn. ${ }^{2}$

In more recent years, existential-phenomenological psychology has continued to thrive across the continent of Europe. Indeed, recent research suggests that Europe, the very birthplace of existential-phenomenological psychology, is the region of the world in which existential-phenomenological psychology remains to have the greatest influence. ${ }^{1}$ Existential-phenomenological psychology increases in interest on the continent of Europe every year and constantly has new developments. Perhaps the most important development in the past few decades has been the establishment of the Society for Existential Analysis in London in $1988 .^{38}$ This organization, which the highly influential therapist Emmy van Deurzen founded, was formed as a dedication to furthering the development of existential-phenomenological psychology around the world. The society is known for its variety of events and activities, such as discussion forums, conferences, and seminars. ${ }^{39}$ Most notable of all of the society's activities, however, is the Journal of the Society for Existential Analysis. This is the society's peer-reviewed, academic journal, which is dedicated to allowing existential-phenomenological practitioners around the world to engage in the major discussions of existential-phenomenological psychology. It also allows existential-phenomenological psychologists to publish original research and other major contributions related to the field. This publication is perhaps the most important worldwide platform for academic work in existentialphenomenological psychology, making the Society for Existential Analysis a central organization for the movement. ${ }^{40}$ 
The founder of the Society for Existential Analysis, Emmy van Deurzen, is a particularly prominent figure in modern existentialphenomenological psychology, and one could indeed argue that she is the current most influential author on the topic around the world and especially in Europe. In particular, van Deurzen, along with other major figures in the "British School of Existential Psychotherapy" is the source of much influence over existential practice in Australia and in almost all of Europe, excluding only central Europe. ${ }^{2}$ Emmy van Deurzen is companioned with such psychologists as Erik Craig, Alfried Längle, Digby Tantum, Bo Jacobsen, Martin Adams, and countless others in keeping the existential-phenomenological tradition alive in Europe throughout the modern era.

\section{Existential-phenomenological psychology's worldwide influence}

After its initial development in Europe, existential-phenomenological psychology soon began to find a place of interest for cultures across the globe. Varying parts of the world have begun to be adopt Existential-phenomenological psychology and its various sub-movements, many of whose cultural contexts are so different from Europe that one could easily never have expected these places to take any interest in the approach. In a study by Correia, Cooper, and Berdondini, ${ }^{1}$ European institutions for existential psychology only constituted about 52.3\% $(n=67)$ of the 128 total existential psychology institutions found, leaving around $47.7 \%(n=61)$ of these institutions to the rest of the world. The number of individual European practitioners who participated in the study also only constituted about $51.2 \%(n=572)$ of the whole worldwide sample of 1,117 practitioners.

After Europe, the region of the world with the highest influence of existential-phenomenological approaches to psychology was Latin America, with $29.7 \%(n=38)$ of the total number of institutions represented and 26.2\% $(n=293)$ of the total number of practitioners participating in the study.

Australia and North America had very similar characteristics to each other in terms of the influence of existentialphenomenological psychology in these regions. However, North America had a slightly higher number of institutions than Australia at $n=15$, composing $11.7 \%$ of the total sample ( $n=3$ and $2.3 \%$ of the total sample for Australia). North America also had slightly more practitioners than Australia at $n=112$, composing $10 \%$ of the sample $(n=85$ and $7.6 \%$ of the total sample for Australia).

Asia and Africa showed the lowest influence of existential-phenomenological psychology. Asia had about 3.1\% of the institutions discovered in the study $(n=4)$ and $4.7 \%$ of the practitioners discovered $(n=53)$. Africa had $0.8 \%$ of the total number of institutions $(n=1)$ and $0.2 \%$ of the total number of practitioners $(n=2)$.

As can be seen, existential-phenomenological psychology has expanded from its original seclusion in Europe to a vast array of places around the world, although it has been more successful in certain regions than in others.

\section{Existential-phenomenological psychology's reception in the United States}

Eventually, the movement made its way into the United States. The reception of the movement in this nation has been somewhat ambivalent. On one hand, it certainly has enjoyed some success in the U.S., having more influence here than in certain other areas such as Asia and Africa, or even Australia. On the other hand, it has not been nearly as successful in the U.S. as it has been in its birthplace of Europe or even in Latin America. In Correia et al.'s study mentioned above, ${ }^{1}$ the U.S. was found to have 8.6\% $(n=11)$ of the total number of institutions in the study as well as $9 \%(n=101)$ of the total number of practitioners. This seems to imply that while existential-phenomenological psychology has found its way into the U.S., it is still developing here as a movement and struggling to gain prominence in the nation.

The first to bring existential-phenomenological psychology into the U.S. seems to be the esteemed therapist Rollo May. ${ }^{29,}{ }^{36,41-45}$ May began applying the ideas of many of the existential thinkers mentioned above to his therapeutic sessions and found that this approach to therapy worked well for his clients. Seeing the efficacy of existential-phenomenological psychology in action, May began calling for an adoption of more existential ideas into the U.S.'s system of psychology as a means of replacing what he perceived to be a serious reductionistic tendency in most American psychology during his time. May especially pointed to the dominance of such movements as behaviorism and cognitive approaches to psychology and therapy as major examples of this reductionistic tendency. ${ }^{29,44,45}$ May believed that the ideas of the European existentialists would assist in correcting the problems inherent in these movements; however, May also recognized that the U.S. exists in a rather distinct cultural context than Europe. Thus, if existential-phenomenological psychology were to come to the U.S., it would have to be modified to fit the cultural context better. May developed an existential approach to the study and practice of psychology that was more humanistic in flavor than that of most European existential psychology, closely allying himself with psychologists during his time such as Abraham Maslow and Carl Rogers to develop this new movement in American Psychology. May's approach placed more emphasis on individuality than the already mildly individualistic perspectives of European existentialists to better fit the highly individualistic values of the U.S. He placed more focus on human virtues and strengths than the Europeans and gave greater recognition to the 
necessity of some level of isolation and aloneness for the finding of oneself. This set in stone a novel form of existentialphenomenological psychology that would come to be known as the "existential-humanistic" school of existential psychology. This is a sub-movement within the broader existential-phenomenological movement that is fairly unique to the U.S., with only a select few institutions and practitioners dedicating themselves to this school outside of the U.S. ${ }^{1}$

Rollo May's legacy was largely carried on by May's student, colleague, and close friend, Irvin Yalom.6, 46, 47 Yalom, who had earned his degree as a psychiatrist, began training under May and was greatly inspired to continue the work that May had done to bring the existential movement into the U.S. Upon publishing his Magnum Opus, Existential Psychotherapy, ${ }^{6}$ Yalom soon became one of the most influential existential-phenomenological psychologists in the United States and continues even to this day to be seen as the key figure in American existential-phenomenological practice. Much like May, Yalom based much of his theory on his experiences as a therapist rather than on systematic research, as these writers were both writing in a time in the U.S. when qualitative and especially phenomenological research methods were widely unpopular. However, their insights are still highly valued by many American psychologists, even outside of the existential-phenomenological tradition.

One of the more contemporary psychologists in the existential-phenomenological tradition in the U.S. is Kirk Schneider. Kirk Schneider, like Yalom, was a student of Rollo May who was highly influenced by May to push for an existential paradigm in American psychology. He is the president of the Existential-Humanistic Institute (EHI), and much of his influence within the movement of existential-phenomenological psychology comes from his involvement in recent major texts in the field, such as the recent Wiley World Handbook of Existential Therapy ${ }^{2}$ as well as various publications in the Journal of the Society for Existential Analysis and other journals such as the Journal of Humanistic Psychology, of which he is the former editor. ${ }^{48}$ Along with continuing the development of the existential-humanistic discipline founded by May, Schneider is also largely responsible for the development of what is now termed "existential-integrative therapy." This recent addition to the movement of existential-phenomenological psychology involves an integration of other psychological and therapeutic approaches, such as psychoanalysis or cognitivebehavioral therapy, into an approach with prioritized existential foundations. This integration of other paradigms into a fundamentally existential approach to psychology helps to keep existential-phenomenological psychology relevant in the U.S. over the constantly changing times in this culture as well as assisting the approach's acceptance within the American scientific community (which is often even more rigorous than that of Europe). ${ }^{2}$

Schneider also has the potential for yet greater influence over the existential-phenomenological movement in the U.S. now that he is a candidate for the 2020 election of the next American Psychological Association (APA) president. According to Schneider's candidate statement, ${ }^{49}$ the U.S. is currently faced with a number of existential crises which must be handled by psychology in order to promote better public mental health across the nation. He believes that this can be achieved with a greater commitment to a "whole-person, integrative orientation to our profession"49 — a statement that is undoubtedly motivated by his existentialhumanistic and existential-integrative approach to psychology. Schneider also lists three primary aims that he would like to fulfill as the APA's new president: greater inclusion of holistic and relational approaches to healthcare, the advocacy of a "psychologist general" office in which an expert in evidence-based integrative practices would collaborate with other agencies to counteract current public mental health crises, and structured dialogue groups which would discuss the highly divisive and polarized state that the U.S. currently faces. ${ }^{49}$ Although Schneider uses language in his platform that is more familiar to the rest of the American psychological community (as opposed to the somewhat esoteric language used by many existential phenomenologists,) the existential and phenomenological foundations for his platform are undeniable, and if Schneider is successful in becoming elected as the next president for the APA, then this will prove to be a significant accomplishment in the development of this movement within the U.S.

Another significant development of existential and phenomenological approaches to psychology was the foundation of the Simon Silverman Phenomenology Center (SSPC) at Duquesne University by Amedeo Giorgi, along with John Sallis. Giorgi and Sallis founded the SSPC to be a "live center" for research and new developments in phenomenology. ${ }^{50}$ While most of the leaders in existentialphenomenological psychology in America mentioned above were more concerned with developing and applying an existentially and phenomenologically oriented psychotherapy, Giorgi and his colleagues at Duquesne University have been more concerned with developing a research method in the phenomenological tradition that could be used in this movement. ${ }^{51-55}$ While May, Yalom, and Schneider seem to be disenchanted with the research paradigms most prevalent in the U.S., and thus choose to base their theories on practical experience in therapy rather than systematic research (Schneider being an occasional exception), the psychologists at the SSPC sought to develop a new research paradigm in the U.S. which would rather prioritize phenomenological methodologies, and thus be more useful in the field of phenomenological psychology. They were eventually successful in doing so, putting together the Journal of Phenomenological Psychology — the first peer-reviewed journal dedicated to research in psychology from the phenomenological tradition. This was a breakthrough event in the history of existential-phenomenological psychology, as the movement now had a way to publish original research in its own tradition that would be respected in the scientific community. One should note that the SSPC does not necessarily constrict itself purely to existential phenomenology, but rather 
devotes itself to research and developments in all areas of phenomenology. However, as mentioned in the first section of this article, since Heidegger's fusion of phenomenological thought with existential thought, existential phenomenology has become one of the most prominent forms of phenomenological study in all fields. Because of this, the development of such a center as the SSPC inherently assists in bringing existential phenomenology, and especially existential-phenomenological psychology, into the U.S.

Eventually, other schools in the U.S. began developing their own programs in phenomenological psychology, often as a result of Duquesne University graduates going on to become professors at these schools. One of the most notable examples of this is the University of West Georgia, with Duquesne University graduates Chris Aanstoos (retired), Eric Dodson, Alan Pope, and Nisha Gupta, which is one of few American schools other than Duquesne University with a doctoral program in phenomenological psychology. ${ }^{56}$ Another notable example is Seattle University, with Duquesne University graduate Steen Halling, which offers an MA in psychology with a particular focus on phenomenological psychology (including existential-phenomenological psychology). ${ }^{57}$ The University of Dallas, with Duquesne University graduates Scott D. Churchill, Gilbert Garza, and Stephanie Swales, also offers multiple Master's programs in phenomenological psychology. ${ }^{58}$ Point Park University, with Duquesne University graduates Brent Robbins, Robert McInerney, Kurt Kumler, and Autumn Redcross, also offers a Psy.D. in psychology with a phenomenological focus. ${ }^{59}$ Finally, Fordham University also has the Duquesne University graduate Frederick Wertz, who specializes in qualitative research methods and phenomenological and existential psychology at this university. ${ }^{60,} \mathrm{~J}$ One should also note the influence of Saybrook University on the existential-phenomenological movement in Psychiatry, which, despite not having many direct connections to Duquesne University or any of the other universities mentioned above, offers an M.A. and a Ph.D. degree in Psychology with humanistic, existential, and transpersonal specializations as well as a Ph.D. in clinical psychology that draws upon similar humanistic, existential, and transpersonal influences. ${ }^{61}$ Saybrook University was, in fact, founded by the Association for Humanistic Psychology (AHP)K — an association dedicated to further developments of "Third Force" psychologies (humanistic, existential, and transpersonal psychology) in the U.S. ${ }^{2}$ Saybrook University is unique in this regard, for it is one of few institutions in the U.S. founded specifically for specialization in the humanistic and related movements in psychology, making it a noteworthy contributor to the movement of existential-phenomenological psychology in the U.S.

Despite these successes of existential-phenomenological psychology in the U.S., the movement has still faced, and continues to face, many threats ${ }^{\mathrm{L}}$ to its development in this country. As mentioned above, the movement tends to be very dissonant with the traditional scientific standards of American psychology, which much prefers quantitative and experimental methods to studying psychology than is usually offered by the existential-phenomenological approach. One can see this highly positivistic focus in existential-phenomenological psychology's first great competitor in the U.S.: behaviorism. Because of behaviorism's incredibly positivistic mandates of observing human behavior specifically, and ignoring such phenomena as consciousness, emotions, cognitions, or - seemingly the worst of all to early behaviorists - free will, seeing all of these as not being scientifically measurable, ${ }^{62-64}$ behaviorism was set in stark opposition to existential phenomenology. This is due to existentialphenomenological psychology's dedication to studying the unity between objective and subjective phenomena, always attempting to connect observable behaviors with some deeper phenomenon that is only understandable through the acknowledgement of consciousness. The popularity of this radical approach to behaviorism in the U.S. during the time when existentialphenomenological psychology was first introduced to the country immediately set the movement up against a powerful threat to its existence. ${ }^{29,44,45}$ Of course, this approach to behaviorism began falling out of favor quickly, as people began to recognize the necessity of acknowledging phenomena less tangible than behavior - even modern behaviorism has begun to acknowledge that they must assume some form of consciousness to exist in psychology (see, for instance, source 65). However, the challenge was far from over.

Even after behaviorism began to pose less of a threat to existential-phenomenological psychology, the emphasis on collecting quantitative data over more qualitative procedures in research has never ended. This continues to be the main threat to existentialphenomenological psychology's existence, as its more qualitative methods to studying psychology are frequently looked down upon by respected leaders in American academic psychology. One particularly prominent threat right now is the development of "experimental existential psychology," which studies the same topics as existential-phenomenological psychology except with more experimental methodologies. ${ }^{10}$ Because this movement applies methodologies that are more accepted in the U.S.'s scientific community to the same topics that existential phenomenology studies, it can easily replace existential phenomenology as the leading source of information on these topics. Indeed, this movement seems already to be gaining more attention than the original tradition of existential-phenomenological psychology.

It should be clarified, of course, that existential-phenomenological psychology need not necessarily invalidate the more accepted scientific traditions in the U.S. altogether. Though some leaders in the movement may be distrustful of experimental and quantitative methods, ${ }^{\mathrm{M}}$ there are those that also believe in setting up a dialogue between these methodologies and the phenomenological methodologies to which they ascribe. ${ }^{\mathbf{N}}$ It may seem, indeed, that it would serve the movement best to take this 
latter position, as this may avoid a fundamental threat to the U.S.'s cultural values, which would, of course, ensure the termination of existential-phenomenological psychology's transition into the nation. This approach would allow for a harmonious relationship between each tradition, which would ease the competition that currently exists between existential phenomenology and its more successful "opponents." In particular, experimental existential psychology has the potential to become more of an ally to existential-phenomenological psychology than a competitor if academics from both traditions can use their differences to complement each other and expand upon each other's theories. There have also been many developments in the U.S. recently that have worked to the favor of existential-phenomenological psychology's more qualitative focus in research. For instance, Division 5 of the APA added a new subdivision known as the Society for Qualitative Inquiry in Psychology (SQIP) in the year 2011 and changed its name from "Evaluation, Measurement, and Statistics" to "Quantitative and Qualitative Methods" in 2014 in order to represent a more equitable recognition of quantitative and qualitative methods as equally valuable research approaches. ${ }^{66}$ Recent challenges to the traditional quantitative-qualitative dichotomy in research have also proven favorable for existentialphenomenological psychology. For instance, the possibility of mixed methods research is promising in its potential for synthesizing phenomenological psychology with some of the more respected traditions in psychology. Some recent figures in existential-phenomenological psychology have begun to recognize the value that methodological pluralism and mixed methods may have for the movement, calling into question psychology's history of dichotomizing qualitative research methods from quantitative ones. ${ }^{67,}{ }^{68}$ The scene for qualitative research has certainly become more favorable in the U.S.; however, it continues to exist as more of an alternative to quantitative methods than as a leading tradition in itself, ${ }^{69}$ and regardless of how most existential-phenomenological psychologists approach the situation, the hostile environment that it must confront in the U.S. is sure to be an issue in its development for many years to come.

\section{THE FUTURE OF EXISTENTIAL-PHENOMENOLOGICAL PSYCHOLOGY}

Despite having enjoyed many successes, existential-phenomenological psychology retains many tasks to complete before it can become a truly respected approach to psychology around the world. Emmy van Deurzen ${ }^{70}$ emphasizes the necessity for existential-phenomenological psychologists to remain flexible in the upcoming thirty years and to be willing to adapt to the changing cultural and historical context of the world. If the movement is not open to adapting itself to best suit the needs of those it serves, then it is sure to fail its goal of persisting and expanding. However, if it also allows itself to change its fundamental principles in the name of becoming more accepted, then it will no longer be the same movement. Thus, those who are deeply involved in the movement must reflect very deeply on what should and should not be adapted in the paradigm to fit the social context in which it continues to develop - a task that will certainly not be easy. Indeed, one could say that existentialphenomenological psychology must subject itself to its own critical processes and must reflect upon its own existence as a collective intellectual movement to understand its relation to the world in which it is developing.

This challenge, a worldwide concern for existential-phenomenological psychology, seems to be especially relevant in the United States. Because of existential-phenomenological psychology's unique position in the U.S., as a movement that has on one hand been somewhat accepted into the social climate and on the other hand is still new and suspicious to many, those who seek to further the movement's development must choose their actions very carefully. They must ensure that no other authorities manage to take away the movement's foundations and force it to conform to any criteria to which it does not belong. However, they must also be careful not to take away the foundations of traditional American psychology either. They must critique the shortcomings of other approaches to psychology in America, but they must not allow this to become an argument for the dominance of this movement over these other movements. They must also be aware of the vast diversity of people peculiar to the U.S., for the U.S.'s heterogeneous population calls for approaches that can constantly adapt to best fit each person with whom it works.

Despite the uncertainty of the movement's future, there is still much potential to further the development of existentialphenomenological psychology in the U.S. Existential-phenomenological psychology could prove helpful, over time, with many of the U.S.'s contemporary issues. For instance, it could help American citizens to find their place in a social environment that is ever-changing and constantly readapting to new situations. It can help these citizens, who live in an increasingly individualistic cultural context, to understand and make peace with the isolation that is inherent in such a social phenomenon. It can also help some of the many people in the U.S. with multicultural backgrounds to make sense out of who they are and what their differing and occasionally conflicting identities mean for them. Most importantly, however, may be existential-phenomenological psychology's capabilities in confronting the ongoing COVID-19 pandemic, which is bound to raise various existential issues for people around the world and particularly in the U.S. ${ }^{\circ}$ With much hard work and perseverance, and perhaps some good fortune, the existential-phenomenological movement in psychology will come to thrive in the U.S.

\section{CONCLUSION}

The existential-phenomenological movement in psychology has the potential for much success and contribution in American psychology but has not yet reached its highest potential in this region. This paper, in providing a comprehensive account of the history and major figures of this lesser-known movement, is offered to help the movement become more familiar to American 
social scientists and laypeople alike and to help this audience to know where to start looking to gain an understanding of this perspective. An argument for adopting more existential-phenomenological principles is also provided, including a discussion of the relevant issues to modern American society which existential-phenomenological psychology can tackle and a review of how the movement's influence can be sustained and increased. In time, if this emerging movement becomes familiar enough to influential American psychologists, its contributions can be realized to their highest benefit to American society.

\section{ACKNOWLEDGMENTS}

The author of this paper thanks his faculty advisor, Dr. Jude Gallik, for her generosity in putting time and effort into helping him get this paper published. The author also thanks Dr. Sam Dreeben, his academic advisor at the time of authoring this paper, for encouraging him to take advantage of the opportunity to become published in this journal. The author also thanks his good friend, Alexandra Salinas, for her feedback on the contents of the paper, which helped the author to refine this article into a better paper. Finally, the author thanks all of the authors and other contributors to the references used in this paper for their assistance in making this literature review possible.

\section{FOOTNOTES}

A. Notably, Sigmund Freud also attended these lectures by Brentano. ${ }^{2}$ This fact is highlighted by various scholars to show the differences between Freud's interpretation of Brentano's concept of intentionality and Husserl's interpretation. This divergence seems to reflect a complex relationship between phenomenology and psychoanalysis that would develop soon after these two figures attended these lectures.

B. See also Heidegger's works Discourse on Thinking ${ }^{71}$ and Introduction to Metaphysics. ${ }^{72}$

C. Or, in Jaspers' own terminology, "Philosophy of Existence", as he proposed to call it in his 1938 book of the same name (translated into English in 1971). ${ }^{28}$

D. NOTE: In this article the term "anthropology" should not be confused with its general usage in reference to the study of "cultural anthropology", which studies the differences between cultural and ethnic groups across space and time. In the sense used here, "anthropology" simply refers to a study of what it means to be human.

E. Some of these thinkers' works can be found in source 36 .

F. "Daseinsanalyse" in the original language of German. This term has been given many translations, such as "Daseinsanalysis" (as seen above), existential analysis, ${ }^{36}$ and "Dasein-analysis". ${ }^{73}$ Because of the confusion these differing translations have created, I have decided simply to use the most common translation, despite some flaws it may have. ${ }^{73}$

G. A few of Binswanger's works can be found in source $\mathbf{3 6}$.

H. See his works in source 36 .

I. This school has had to be renamed many times due to each name's misleading nature, and no perfect name for it truly exists. It was first named the "London School of Existential Psychotherapy," although its founders had to change this name because it is practiced in areas outside of London. It was then changed to the "British School of Existential Psychotherapy," but major proponents had to change it from this name since it is practiced in countries outside of Great Britain as well. For a brief period, some wanted to call it the "European School of Existential Psychotherapy," though this trend ended quickly due to its already rapid growth to regions outside of Europe. This name also fell out of favor because the number of existential therapies based in Europe are so numerous that no single one can be fairly called "the" European School of Existential Psychotherapy. Most recently, experts have been settling on calling it the "existential-phenomenological" school of psychotherapy, although this was very tentative, as all primarily existentially oriented schools of psychotherapy are existentialphenomenological therapy. ${ }^{2}$ In this paper, I use the name of "the British School of Existential Psychotherapy", as I felt this to be the most fair name and also felt that it would eliminate the confusion that would inherently be present were I to use the name "existential-phenomenological therapy." One should remember that I had stated that all of the existential therapeutic paradigms discussed in this article would be a part of the existential-phenomenological movement.

J. This list is by no means exhaustive of all of the schools and professionals influenced by Duquesne University. I am sure that there are other schools in the U.S. with Duquesne University graduates as well as other Duquesne University graduates at the schools listed whom I did not mention. I was only able to list all of the schools that I could find and all of the faculty members there who were confirmed to be Duquesne University graduates either on the university websites or by common knowledge. Also, one should note that Duquesne University graduates are not the only American psychologists who practice phenomenology. There are plenty of practitioners of phenomenological psychology at the universities listed as well as others who did not study at Duquesne University at all. The purpose of my mentioning the names of these psychologists is to show the specific influence of Duquesne University over phenomenological psychology in the U.S.

K. This school was even originally named the "Humanistic Psychology Institute" to reflect the highly humanistic-based thinking of its founders. It was later re-named "Saybrook University", after a famous conference named the "Old Saybrook Conference" in which various leading figures in the "Third Force" movement in American psychology, including leaders of the existential-humanistic movement, convened to discuss the philosophy and direction which the AHP should take.2 
L. Some readers may find the word "threat" to be a bit strong, but by "threat" I do not necessarily mean a force actively working to suppress existential-phenomenological psychology. I simply mean any force that either actively attempts such an action or simply has this effect passively. Some of the "threats" to existential-phenomenological psychology discussed may have actively attempted to discount the movement, but many of them had no such intention and simply threatened the movement because of their greater success in the U.S.

M. Irvin Yalom, for instance, tended to view most experimental studies with skepticism.

N. Phenomenologists in the tradition of Interpretative Phenomenological Analysis (IPA), for instance, prefer to view their method as a complement to experimental methods rather than a replacement of them. ${ }^{74}$ Also, as mentioned later in the article, figures such as Joël Vos, Mick Cooper, Edgar Correia, and Meghan Craig ${ }^{67}$ as well as Mick Cooper and John McLeod $^{68}$ have begun promoting a pluralistic approach to research and counselling methodology in recent years, arguing that a balanced presence of all research methods is the most effective way to contribute to the field of psychology.

O. One should take note of the fact that at the time this paper was written, the U.S. had the highest number of reported COVID-19 cases out of every country in the world..$^{75}$ This may no longer be true by the time this article is published, but regardless of whether it is or not, the fact that the U.S. was, at one point, the country with the largest impact of COVID-19 is certain to make existential concerns more relevant to people in this nation for many years to come.

\section{REFERENCES}

1. Correia, E. A., Cooper, M., and Berdondini, L. (2014) The worldwide distribution and characteristics of existential counsellors and psychotherapists, Journal of the Society for Existential Analysis 25(2), 321-337. https:/ / www.researchgate.net/profile/Edgar_Correia/publication/272686791_The_worldwide_distribution_and_characteristics_of_existential _counsellors_and_psychotherapists/links/555b0ff508ae980ca611bdf0.pdf

2. Deurzen, E. van, Craig, E., Längle, A., Schneider, K.J., Tantam, D., and Plock, S. du. (Eds.). (2019) The Wiley world handbook of existential therapy, Wiley, Hoboken.

3. Jacobsen, B. (2007) Invitation to existential psychology: A psychology for the unique human being and its applications to therapy, Wiley, West Sussex.

4. Jacobsen, B. (2007) Authenticity and our basic existential dilemmas: Foundational concepts of existential psychology and therapy, Journal of the Society for Existential Analysis, 18(2), 288-296.

5. Boss, M. (1979) Existential foundations for medicine and psychology (Conway, S., and Cleaves, A., Trans.), Aronson, Lanham.

6. Yalom, I.D. (1980) Existential psychotherapy, Basic Books, New York.

7. Husserl, E. (2013) Ideas: General introduction to pure phenomenology (Gibson, W.R.B., Trans.), Routledge, New York.

8. Deurzen, E. van. (2014) Structural existential analysis (SEA): A phenomenological research method for counselling psychology, Counselling Psychology Review 29(2), 54-66. https://shop.bps.org.uk/publications/journals-and-periodicals/counsellingpsychology-review-vol-29-no-2-june-2014.html

9. Heidegger, M. (1962) Being and time (Macquarrie, J., and Robinson, E., Trans.), Harper \& Rowe, New York.

10. Evangelista, P. (2018) Existential-phenomenological psychologist's action, Journal of the Society for Existential Analysis 29(2), 282-290. https:/ / community.existentialanalysis.org.uk./sea-journals

11. Greenberg, J., Koole, S.L., and Pyszczynski, T. (Eds.). (2004) Handbook of experimental existential psychology, Guilford, New York.

12. Kierkegaard, S. (1985) Fear and trembling (Hannay, A., Trans.), Penguin Books, New York.

13. Kierkegaard, S. (2014) The concept of anxiety: A simple psychologically oriented deliberation in view of the dogmatic problem of hereditary sin (Hannay, A., Trans.), Liveright, New York.

14. Kierkegaard, S. (1989) The sickness unto death: A Christian psychological exposition for edification and awakening (Hannay, A., Trans.), Penguin Books, New York.

15. Nietzsche, F. (1974) The gay science: With a prelude in rbymes and an appendix of songs (Kaufmann, W., Trans.), Vintage Books, New York.

16. Nietzsche, F. (1954) The portable Nietzsche (Kaufmann, W., Trans.), Penguin Books, New York.

17. Nietzsche, F. (1967) The birth of tragedy and the case of Wagner (Kaufmann, W., Trans.), Random House, New York.

18. Nietzsche, F. (2019) Beyond good and evil (Zimmern, H., Trans.), Arcturus, London.

19. Husserl, E. (1977) Phenomenological psychology: Lectures, summer semester (Scanlon, J., Trans.), Nijhoff, The Hague.

20. Husserl, E. (1973) Experience and judgement: Investigations in a genealogy of logic (Churchill, L.S., and Ameriks, K., Trans.), Northwestern University Press, Evanston.

21. Correia, E.A., Cooper, M., and Berdondini, L. (2015) Existential psychotherapy: An international survey of the key authors and texts influencing practice, Journal of Contemporary Psychotherapy, 45(1), 3-10. https:/ / link.springer.com/article/10.1007/ s10879$014-9275-y$

22. Hein, S.F., and Austin, W.J. (2001) Empirical and hermeneutic approaches to phenomenological research in psychology: A comparison, Psychological Methods, 6(1), 3-17. https:/ / doi.org/10.1037/1082-989X.6.1.3

23. Levinas, E. (1989) Ethics as first philosophy, in The Levinas Reader (Hand, S., Ed.), 75-87, Blackwell, Malden. 
24. Sartre, J.-P. (1956) Being and nothingness: An essay on phenomenological ontology (Barnes, H.E., Trans.), Philosophical Library, New York.

25. Sartre, J.-P. (1957) Existentialism and human emotions (Maconber, P.M.C, Trans.), Philosophical Library, New York.

26. Beauvoir, S. de. (2009) The second sex (Borde, C., and Chevallier, S., Trans.), Jonathan Cape, London.

27. Beauvoir, s. de. (1948) The ethics of ambiguity (Fretchman, B., Trans.), Citadel Press, Secaucus.

28. Jaspers, K. (1971) Philosophy of existence (Grabau, R.F., Trans.), University of Pennsylvania Press, Philadelphia.

29. May, R. (1967) Psychology and the human dilemma, Norton, New York.

30. Butler, J. (1986) Sex and gender in Simone de Beauvoir's Second Sex, Yale French Studies 72, 35-49.

31. Buber, M. (1970) I and thou (Kaufmann, W., Trans.) Scribner, New York.

32. Merleau-Ponty, M. (1962) Phenomenology of perception (Smith, C., Trans., Routledge \& Kegan Paul, London.

33. Merleau-Ponty, M. (1968) The visible and the invisible (Lingis, A., Trans.), Northwestern University Press, Evanston.

34. Jaspers, K. (1997) General psychopathology (Hoenig, J., and Hamilton, M.W., Trans.) Vols. 1 \& 2, John Hopkins University Press, Baltimore.

35. Jaspers, K. (1968) The phenomenological approach in psychopathology, British Journal of Psychiatry 114, 1313-1323.

36. May, R., Angel, E., and Elleberger, H.F. (Eds.). (1958) Existence: A new dimension in psychiatry and psychology, Basic Books, New York.

37. Frankl, V. (2006) Man's search for meaning (Lasch, I., and Frankl, V., Trans.), Beacon Press, Boston.

38. Society for Existential Analysis, About the SEA, https://existentialanalysis.org.uk/about-the-sea/ (accessed Apr 2020)

39. Society for Existential Analysis, Events: SEA community, tickets, and events, bttps:// community.existentialanalysis.org.uk/events (accessed Aug 2020)

40. Society for Existential Analysis, Journal, https:// existentialanalysis.org.uk/publications/journal/ (accessed Apr 2020)

41. May, R. (1969) Love and will, Norton, New York.

42. May, R. (1975) The courage to create, Norton, New York.

43. May, R. (1977) The meaning of anxiety, Norton, New York.

44. May, R. (1981) Freedom and destiny, Dell, New York.

45. May, R. (Ed.) (1983) The discovery of being: Writings in existential psychology, Norton, New York.

46. Yalom, I.D. (1989) Love's executioner and other tales of psychotherapy, Basic Books, New York.

47. Yalom, I.D. (2008) Staring at the sun: Overcoming the terror of death, Jossey-Bass, San Francisco.

48. Schneider, K.J., About me, https://kirkjschneider.com/about/ (accessed Apr 2020)

49. American Psychological Association (APA), Kirk Schneider, PhD: 2020 President-elect candidate, https:// www.apa.org/about/governance/elections/president-elect-candidate-schneider (accessed Sep 2020)

50. McCurry, J., and Binnie, C.R. (2019) The Simon Silverman Phenomenology Center at Duquesne University and phenomenology in North America, in Contributions to Phenomenology: The Reception of Husserlian Phenomenology in North America (Ferri, M.B., Ed.) vol. 100, Springer Nature, Basel.

51. Girogi, A. (1970) Psychology as a buman science: A phenomenologically based approach. Harper \& Rowe, New York.

52. Giorgi, A. (Ed.) (1985) Phenomenology and psychological research, Duquesne University Press, Pittsburgh.

53. Laubscher, L. (2016) Introduction to psychology as a buman science, Cognella Publishers, San Diego.

54. Fischer, C.T., Laubscher, L., and Brooke, R. (2016) The qualitative vision for psychology: An invitation to a buman science approach, Duquesne University Press, Pittsburgh.

55. Wertz, F.J. (2005) Phenomenological research methods for counseling psychology, Journal of Counseling Psychology, 52(2), 167177. https:/ / doi.org/10.1037/0022-0167.52.2.167

56. University of West Georgia, Faculty and staff members (Psychology), https:// wmw.westga.edu/academics/coss/psychology/facultystaff.php (accessed Apr 2020)

57. Seattle University, MA in Psychology: Faculty and staff, https://www.seattleu.edu/artsci/map/faculty-and-staff/ (accessed Apr 2020)

58. University of Dallas, Psychology faculty directory, https:// udallas.edu/constantin/academics/programs/psychology/faculty/ (accessed Apr 2020)

59. Point Park University, Psychology faculty and staff, https:// www.pointpark.edu/Academics/Schools/SchoolofArtsandSciences/Departments/Psychology/Psychology\%20Faculty/index (accessed Apr 2020)

60. Fordham University, Psychology faculty and staff, https://www.fordham.edu/info/21660/psychology_faculty_and_staff(accessed Apr 2020)

61. Saybrook University, Humanistic and clinical psychology programs, https:// wmw.saybrook.edu/areas-of-study/ bumanistic-clinicalpsychology/ (accessed Aug 2020)

62. Watson, J.B. (1913) Psychology as the behaviorist view it, Psychological Review, 20, 158-177. https:// pure.mpg.de/rest/items/item_2404108/component/file_2404107/content

63. Skinner, B.F. (1938) The behavior of organisms: An experimental analysis, Appleton-Century, New York. 
64. Skinner, B.F. (1971) Beyond freedom and dignity, Knopf/Random House, New York.

65. Bandura, A. (1963) Social learning and personality development, Holt, Rineheart and Winston, New York.

66. Society for Qualitative Inquiry in Psychology, About SQIP, http://sqip.org/about/ (Accessed Aug 2020)

67. Vos, J., Cooper, M., Correia, E., and Craig, M. (2015) Existential therapies: A review of their scientific foundations and efficacy, Journal of the Society for Existential Analysis, 26(1), 49-69.

68. Cooper, M., and McLeod, J. (2011) Pluralistic counselling and psychotherapy, SAGE Publications, London.

69. Rubin, J.D., Bell, S., and McClelland, S.I. (2017) Graduate education in qualitative methods in U.S. psychology: Current trends and recommendations for the future, Qualitative Research in Psychology, 15(1), 29-50. https:/ / www.tandfonline.com/doi/abs/10.1080/14780887.2017.1392668

70. Deurzen, E. van. (2019) Facing an uncertain future: The next 30 years of existential therapy, Journal of the society for Existential Analysis, 30(1), 4-17. https:/ / community.existentialanalysis.org.uk/ sea-journals

71. Heidegger, M. Discourse on thinking (Anderson, J.M., and Freund, E.H., Trans.), Harper \& Rowe, New York.

72. Heidegger, M. (2000) Introduction to metaphysics (Fried, G., and Polt, R., Trans.), Yale University Press, New Haven.

73. McCall, R.J. (1983) Phenomenological psychology: An introduction: With a glossary of some key Heideggerian terms, University of Wisconsin Press, Madison.

74. Shinebourne, P. (2011) The theoretical underpinnings of interpretative phenomenological analysis (IPA), Journal of the Society for Existential Analysis, 22(1), 16-31. https:/ / community.existentialanalysis.org.uk/ sea-journals

75. WorldOMeter, COVID-19 Coronavirus pandemic update, https:// wmw.worldometers.info/coronavirus/ (accessed Apr 2020)

\section{ABOUT STUDENT AUTHOR}

Christopher Zieske completed this manuscript as a senior at Schreiner University, Kerrville, Texas. He will graduate with a B.A. in Psychology in the spring of 2021. After graduation, he plans to pursue a Ph.D. in Clinical Psychology with a focus on applying existential-phenomenological psychology to clinical research and practice. His goal is to become a clinical psychologist with emphasis on both research and practice as well as a mentor for graduate students.

\section{PRESS SUMMARY}

This paper reviews the "existential-phenomenological" approach to psychology in terms of its basic principles and the history of its development. It starts by explaining the theory and practice of existential-phenomenological psychology and then gives a survey of many of the most influential figures in the movement's history. A particular focus is placed on existentialphenomenological psychology's success in the U.S., with a discussion of how to further bring the movement into American society presented as well as an observation of the uncertainty surrounding the movement's future, with the potential both for failure and for further success being possible. 